\title{
STABILISASI TANAH LEMPUNG DESA TUMBANG RUNGAN DENGAN ROADBOOSTER UNTUK PERKERASAN JALAN
}

\author{
Evi Meilisa Adhanty ${ }^{(1)}$, Rida Respati ${ }^{(2)}$, Norseta Ajie Saputra ${ }^{(3)}$ \\ Alumni Fak.Teknik UM Palangka Raya ${ }^{(1)}$ \\ Program Studi Teknik Sipil UM Palangka Raya ${ }^{(2)(3)}$
}

\begin{abstract}
ABSTRAK
Tanah merupakan fondasi untuk suatu konstruksi. Fondasi adalah bagian paling bawah dari suatu konstruksi, berfungsi untuk menyalurkan beban langsung dari struktur konstruksi tersebut ke lapisan tanah di bawahnya. Tanah yang mempunyai sifat yang buruk sangat tidak menguntungkan jika digunakan untuk suatu konstruksi, terutama untuk perkerasan jalan raya.

Cara agar daya dukung tanah lempung meningkat adalah dengan melakukan usaha stabilisasi tanah, yaitu dengan menggunakan roadbooster sebagai bahan kimia stabilisainya dan diharapkan mampu memperbaiki sifat tanah lempung tersebut dan memenuhi syarat untuk bahan perkerasan jalan. Pada penelitian ini akan dilakukan stabilisasi terhadap tanah lempung Desa Tumbang Rungan Palangka Raya dengan parameter utama yang digunakan sebagai acuan penelitian yaitu California Bearing Ratio (CBR) rendaman dan Unconfined Compressive Strenght (UCS).

Berdasarkan hasil pengujian tanah lempung Desa Tumbang Rungan Palangka Raya, maka didapat data: CBR rendaman tanah asli 7,89\%, CBR rendaman $0 \%$ roadbooster $76 \%$, CBR rendaman $4 \%$ roadbooster $40,85 \%$, CBR rendaman $8 \%$ roadbooster $27,08 \%$, UCS tanah asli $0,56 \mathrm{~kg} / \mathrm{cm} 2$, UCS $0 \%$ roadbooster 7,30 $\mathrm{kg} / \mathrm{cm} 2$, UCS $4 \%$ roadbooster $7,40 \mathrm{~kg} / \mathrm{cm} 2$, dan UCS $8 \%$ roadbooster $8,30 \mathrm{~kg} / \mathrm{cm} 2$. Dari data CBR terlihat nilai CBR yang tertinggi adalah pada saat pencampuran $0 \%$ roadbooster atau tanpa tambahan roadbooster, sedangkan nilai UCS tertinggi terletak pada pencampuran $8 \%$ roadbooster.
\end{abstract}

Kata Kunci: Tanah lempung, stabilisasi, semen, pasir, roadbooster 
Stabilisasi Tanah Lempung dengan Roadbooster..., Evi ${ }^{(1)}, \operatorname{Rida}^{(2)}, \operatorname{Norseta}^{(3)}$

\section{PENDAHULUAN}

Tanah merupakan fondasi untuk suatu konstruksi. Fondasi adalah bagian paling bawah dari suatu konstruksi, berfungsi untuk menyalurkan beban langsung dari struktur konstruksi tersebut ke lapisan tanah di bawahnya. Konstruksi yang baik yaitu memiliki nilai daya dukung tanah dan kuat tekan bebas yang tinggi. Menurut Dirjen Bina Marga 1976 (dalam Muda, 2011), bahwa tanah yang amat baik memiliki nilai daya dukung tanah $>24 \%$ untuk subgrade dan menurut Hardiyatmo 2006 nilai kuat tekan bebas untuk tanah lempung keras adalah $>400 \mathrm{kN} / \mathrm{m}^{2}$. Daya dukung tanah yang rendah sangat tidak menguntungkan jika digunakan untuk suatu konstruksi, terutama untuk konstruksi perkerasan jalan raya.

Salah satu contoh tanah dengan daya dukung yang rendah adalah tanah lempung Desa Tumbang Rungan Palangka Raya. Secara garis besar tanah lempung memiliki nilai sweling yang besar, plastisitas indeks tinggi, nilai daya dukung yang kecil dan sangat tidak menguntungkan jika digunakan untuk suatu konstruksi, terutama untuk perkerasan jalan raya. Tanah lempung di Desa Tumbang Rungan secara kasat mata dilihat sama seperti tanah lempung lainnya, namun disini tanah itu di gunakan sebagai tempat transportasi yang mana harus memerlukan daya dukung yang besar untuk memikul beban diatas nya. Cara agar daya dukung tanah meningkat adalah dengan melakukan usaha stabilisasi tanah. Menurut Hardiyatmo 2010, stabilisasi tanah adalah untuk menambah kapasitas daya dukung tanah dan kenaikan kekuatan yang akan diperhitungkan pada proses perancangan tebal perkerasan. Stabilisasi tanah umumnya dilakukan dengan dua metode yaitu metode mekanis dan stabilisasi secara kimiawi atau dengan menambahkan bahan kimia.

Stabilisasi yang akan dikerjakan nanti merujuk kestabilisasi secara kimiawi, yang mana bahan kimia yang digunakan adalah roadbooster, dengan penambahan pasir dan semen sebagai perbandingan. Roadbooster adalah bahan kimia larut untuk perkerasan jalan yang didasarkan pada formula murni biologis. Diciptakan di Jerman oleh perusahaan besar konstruksi International $\mathrm{GmbH}$ dan bekerjasama dengan mitra dilebih dari 30 negara diseluruh dunia. Konstruksi jalan dengan
Roadbooster memiliki keuntungan yang signifikan, yaitu penghematan biaya hingga 50\%, 7 (tujuh) kali cepat memproses perkerasan, pencapaian kapasitas beban lebih tinggi ( $>800 \mathrm{MN} / \mathrm{m}^{2}$, respon CBR hingga $1200 \%$ ) dan pengurangan atau pencegahan kerusakan lapisan aspal.

Berdasarkan uraian di atas, maka pengujian yang akan dilakukan berupa stabilisasi tanah lempung secara kimiawi dengan menggunakan bahan campuran aditif roadbooster dengan penambahan pasir dan semen sebagai perbandingan.

\section{KAJIAN PUSTAKA}

Stabilisasi tanah adalah usaha untuk menambah kapasitas daya dukung tanah dan kenaikan kekuatan yang akan diperhitungkan pada proses perancangan tebal perkerasan. Beberapa cara stabilisasi tanah misalnya: pemadatan, mencampur tanah dengan bahan granuler menggunakan tulangan atau perkuatan, penggalian dan pergantian tanah dan lain-lain. Serta, dengan menambahkan bahan kimia (stabilitas secara kimiawi), yaitu dengan roadbooster sebagai bahan stabilisasinya.

Roadbooster adalah bahan kimia larut untuk perkerasan jalan yang didasarkan pada formula murni biologis. Diciptakan di Jerman oleh perusahaan besar konstruksi International $\mathrm{GmbH}$ dan bekerjasama dengan mitra dilebih dari 30 negara diseluruh dunia. Konstruksi jalan dengan roadbooster memiliki keuntungan yang signifikan, yaitu penghematan biaya hingga 50\%, 7 (tujuh) kali cepat memproses perkerasan, pencapaian kapasitas beban lebih tinggi ( $>800 \mathrm{MN} / \mathrm{m}^{2}$, respon CBR hingga $1200 \%$ ) dan pengurangan atau pencegahan kerusakan lapisan aspal.

Perbandingan metode konstruksi jalan yang inovatif (Roadbooster) dan konvensional di Jerman: 
Stabilisasi Tanah Lempung dengan Roadbooster..., Evi ${ }^{(1)}, \operatorname{Rida}^{(2)}, \operatorname{Norseta}^{(3)}$

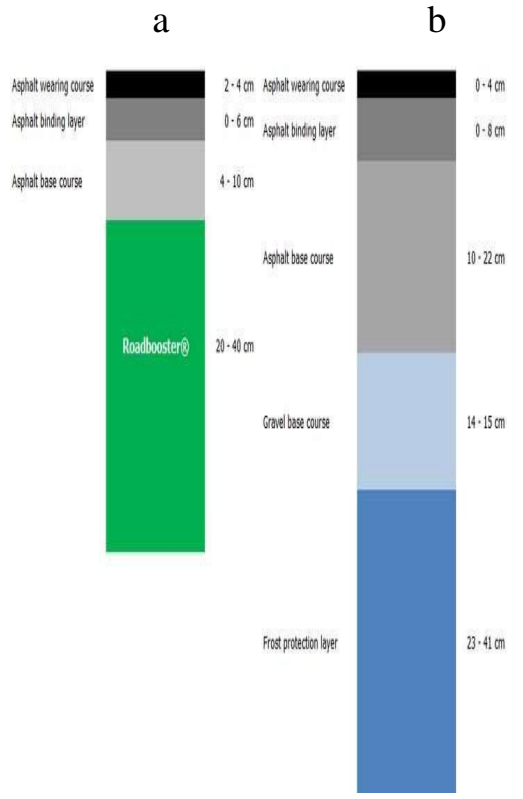

Gambar 2.2 Perbandingan Konstruksi Jalan

Sumber: http://www.roadbooster.com/en/faq.html (diakses 17 April 2017)

Dengan (a) Konstruksi Menggunakan Roadbooster dan (b) Konstruksi Jalan Konvensional

Proses roadbooster memungkinkan substruktur jalan berkurang secara signifikan. Kemampuan tekanan beban yang sangat tinggi dapat secara signifikan mengurangi lapisan aspal atas dan menghasilkan penghematan biaya yang cukup besar untuk mengganti fungsi dari komponen yang terlalu mahal.

\section{METODE PENELITIAN}

\section{Tempat Penelitian}

Data diperoleh dari pengujian yang dilakukan di Laboratorium Geoteknik Universitas Muhammadiyah Palangkaraya.

\section{Teknik Pengumpulan Data}

Beberapa data yang dikumpulkan untuk penelitian ini terdiri dari dua kategori:

1. Data Primer

Data primer merupakan data yang didapat melalui pengujian langsung di Laboratorium.

2. Data Sekunder
Data sekunder adalah data yang diperoleh dengan mengutip data yang sudah ada buku terdahulu. Data tersebut berupa hasil pengujian laboratorium.

\section{Analisa Data}

Analisis data yang diketahui adalah melakukan inventarisasi terhadap nilai:

1. California Bearing Ratio (CBR) dan Unconfined Compressive Strength (UCS) tanah asli.

2. California Bearing Ratio (CBR) dan Unconfined Compressive Strength (UCS) tanah campuran/stabilisasi.

3. Korelasi nilai CBR dan UCS retak sebelum dan sesudah stabilisasi.

Untuk mempermudah analisis dibuat dalam bentuk grafik dan diagram.

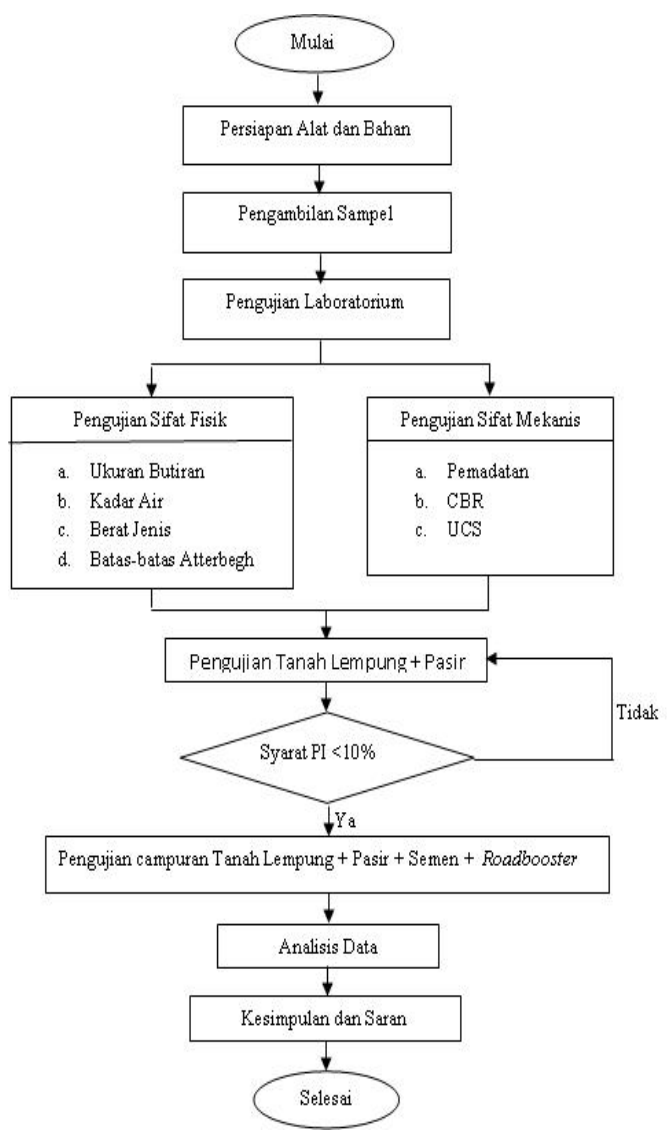

Gambar 3.1. Bagan Alir 
Stabilisasi Tanah Lempung dengan Roadbooster..., Evi ${ }^{(1)}, \operatorname{Rida}^{(2)}, \operatorname{Norseta}^{(3)}$

\section{HASIL DAN PEMBAHASAN}

Adapun karakteristik tanah asli Desa Tumbang Rungan Palangka Raya dapat dilihat pada Tabel 4.1.

Tabel 4.1 Karakteristik Tanah Asli

\begin{tabular}{|c|c|c|}
\hline Tipe Pengujian & Satuan & Hasil \\
\hline Lolos Saring an No. 200 & $\%$ & 93,99 \\
\hline Batas cair (LL) & $\%$ & 50 \\
\hline Batas Plastis (PL) & $\%$ & 28,36 \\
\hline Indeks Plastisitas (PI) & $\%$ & 21,64 \\
\hline Berat Jenis & & 2,60 \\
\hline Berat Isi Kering Maksim um & $\mathrm{gr} / \mathrm{cm}^{3}$ & 1,34 \\
\hline Kadar Air Optimum & $\%$ & 29 \\
\hline CBR & $\%$ & 7,89 \\
\hline UCS & $\mathrm{Kg} / \mathrm{cm}^{2}$ & 0,58 \\
\hline
\end{tabular}

Sumber: Hasil Uji Laboratorium (2017)

Hasil identifikasi terhadap tanah asli merupakan gambaran sifat-sifat dari tanah tersebut Sifat-sifat ini akan dibandingkan beberapa teori, peraturan yang ada/penelitian yang pernah dilakukan. Hal ini terlihat Tabel 4.6.

Tabel 4.6 Hasil Identifikasi Tanah Asli

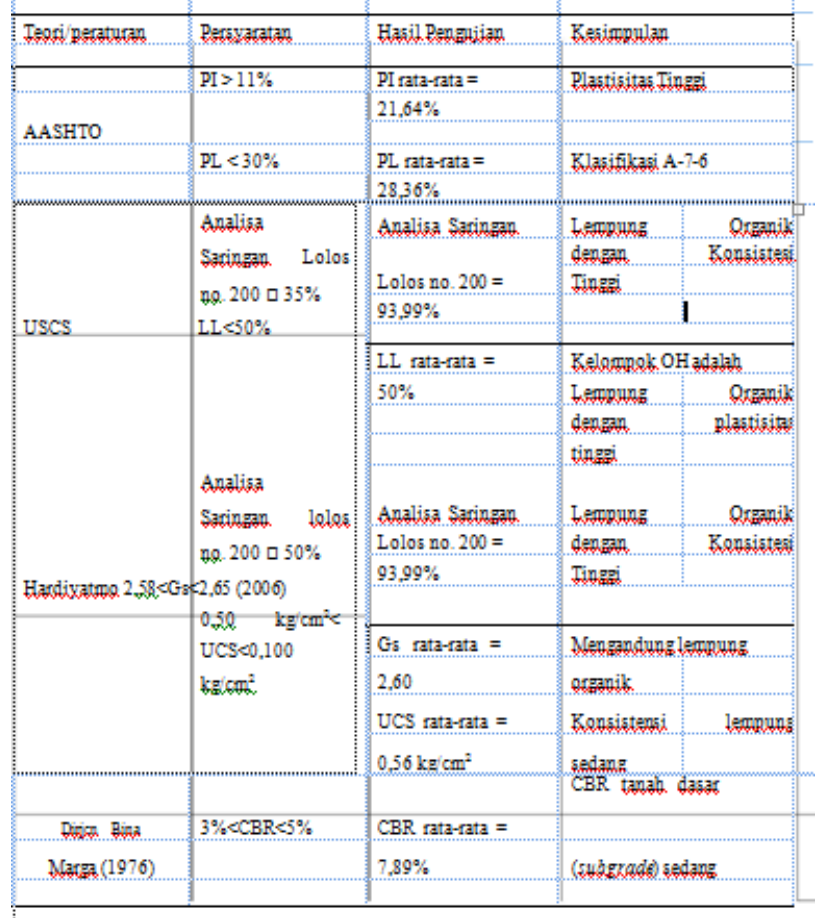

Campuran tanah semen pasir roadbooster meliputi pengujian CBR dan UCS.

1. California Bearing Ratio (CBR)

Adapun CBR campuran tanah, semen, pasir dan roadbooster dapat dilihat pada Gambar 4.11.

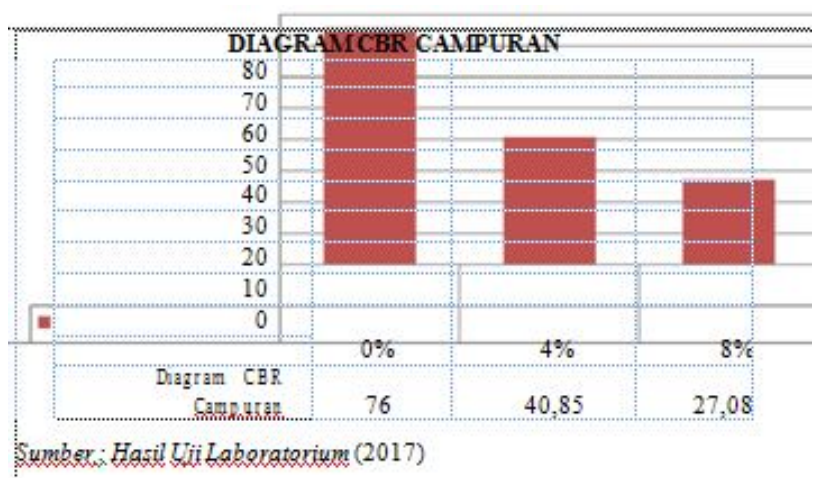

Gambar 4.11 Diagram CBR campuran

Pada Gambar 4.11 menunjukan adanya kecenderungan penurunan nilai CBR seiring dengan penambahan roadbooster. Hal ini terjadi karena semakin banyak penambahan roadbooster semakin bereaksi dengan tanah, sehingga nilai kuat dukung tanah semakin menurun. Namun ketika roadbooster penambahannya semakin besar bukan berarti nilai CBR itu akan terus menerus meningkat, terkadang semakin banyak penambahan kadar roadbooster semakin kurang baik.

\section{Unconfined Compressive Strength (UCS)}

Adapun UCS campuran tanah, semen, pasir dan roadbooster dapat dilihat pada Gambar 4.12 . 


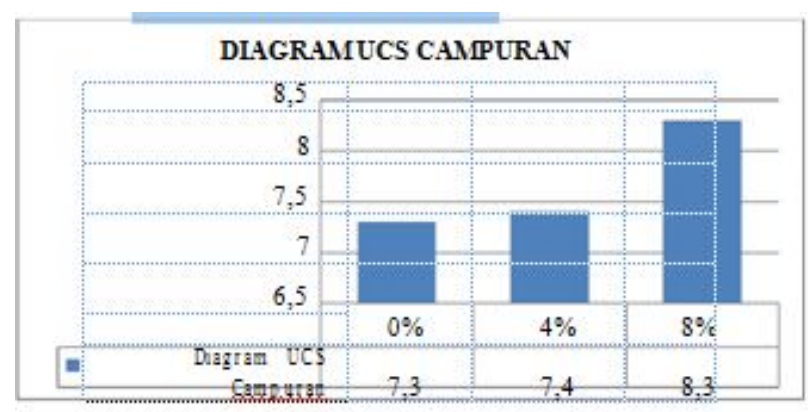

Sumber : Hasil Uji Laboratorium (2017)

Gambar 4.12 Diagram UCS Campuran

Pada Gambar 4.12 dapat dijelaskan bahwa penambahan semen $10 \%$ pada tanah berpengaruh terhadap qu, semakin bertambah pencampuran semen dan roadbooster pada tanah, maka nila qu akan terus meningkat pada masing-masing pencampuran. Terlihat pada nilai kuat tekan yang terjadi pada penambahan campuran roadbooster 8\% nilai UCS meningkat drastis dari kondisi campuran roadbooster $0 \%$ dan $4 \%$. Hal ini menunjukan bahwa jika persen pemakaian roadbooster ditambah saat pengujian UCS membuat nilai UCS terus menerus naik.

Adapun korelasi nilai CBR dan UCS disini akan ditampilkan berupa diagram batang yang dapat di lihat pada Gambar 4.13.

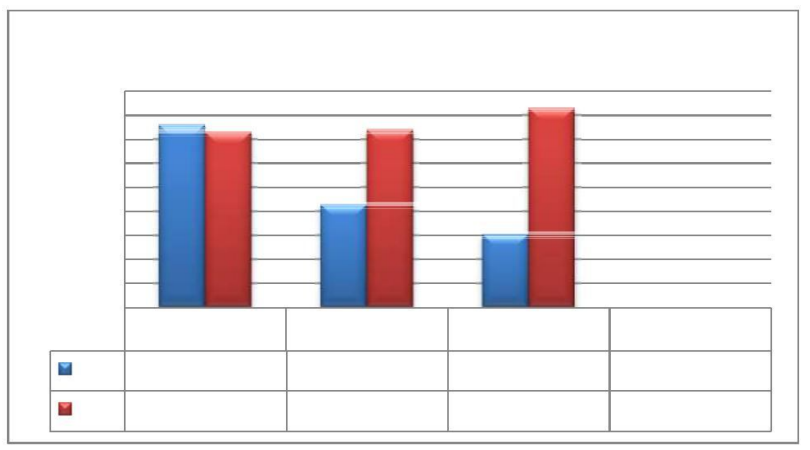

Sumber : Hasil Uji Laboratorium (2017)

Gambar 4.13 Diagram Korelasi Nilai CBR dan UCS

Pada Gambar 4.13 dalam diagram korelasi nilai CBR dan UCS terlihat nilai CBR dan UCS tidak saling berhubungan, dapat dilihat bahwa nila CBR maksimum diperoleh pada penambahan roadbooster $0 \%$ dengan nilai CBR sebesar $76 \%$, sedangkan nilai UCS maksimum diperoleh pada penambahan roadbooster $8 \%$ dengan nilai UCS sebesar $8,30 \mathrm{~kg} / \mathrm{m}^{2}$.

Berdasarkan penelitian dan uraian dalam pembahasan maka dapat ditarik kesimpulan sebagai berikut:

1. Tanah lempung Desa Tumbang Rungan memiliki sifat fisik lempung organik, dengan plastisitas tinggi. Pada kondisi tanah asli menunjukan bahwa batas cair (LL) $=50,00 \%$, batas plastis $(\mathrm{PL})=28,36 \%$, atau menurut USCS tanah lempung Desa Tumbang Rungan termasuk dalam kategori $\mathrm{OH}$. Sedangkan menurut AASHTO tanah lempung Desa Tumbang Rungan termasuk dalam kelompok A-7-5 dengan karakteristik tanah berbutir halus dan plastisitas tinggi.

2. Nilai CBR tanah lempung Desa Tumbang Rungan sebesar 7,79\% dengan berat isi kering sebesar $1,34 \mathrm{gr} / \mathrm{cm}^{3}$ pada kadar air optimum $29,00 \%$, dan memiliki nilai UCS sebesar 0,58 $\mathrm{kg} / \mathrm{cm}^{2}$.

3. Untuk nilai stabilisasi sesuai dengan persyaratan sebelum dilakukan stabilisasi, tanah lempung Desa Tumbang Rungan harus memiliki nilai PI $<10 \%$. Untuk itu dilakukan penambahan pasir sebesar 35\% pada tanah lempung yang ada, dan diperoleh nilai PI sebesar 8,32\% (memenuhi persyaratan) (Hardiyatmo, 2010).

4. Hasil pencampuran tanah lempung, pasir, semen dan roadbooster dapat dilihat pada tabel 5.1 .

Tabel 5.1 Hasil Pengujian CBR dan UCS

\begin{tabular}{|c|c|c|c|c|}
\hline 'Pasir & Semen & Roadbooster & CBR & UCS \\
\hline$(\%)$ & $(\%)$ & $(\%)$ & $(\%)$ & $\left(\mathrm{kg} / \mathrm{cm}^{2}\right)$ \\
\hline & & & & \\
\hline & & 0 & 76 & 7,3 \\
\hline 35 & 10 & 4 & 40,85 & 7,40 \\
\hline & & & & \\
\hline & & 8 & 27,08 & 8,30 \\
\hline
\end{tabular}

5. Pada pengujian $\mathrm{CBR}$, pengaruh roadbooster yang mencapai nilai tertinggi terjadi pada campuran $0 \%$ roadbooster dengan nilai CBR 76\%. Sesuai dengan peraturan Bina Marga maka tanah yang distabilisasi ini dapat digunakan sebagai subgrade jalan raya $(\mathrm{CBR} \geq$ 
Stabilisasi Tanah Lempung dengan Roadbooster..., Evi ${ }^{(1)}, \operatorname{Rida}^{(2)}, \operatorname{Norseta}^{(3)}$

24\%). Sedangkan pada pengujian UCS, pencampuran tanah lempung, semen, pasir dan penambahan roadbooster $8 \%$ menghasilkan nilai qu maksimum sebesar $8,3 \mathrm{~kg} / \mathrm{cm}^{2}$.

6. Untuk stabilisasi menggunakan campuran semen dan roadbooster tidak semua variasi campuran menghasilkan nilai CBR dan nilai UCS yang baik, disisi lain karena kondisi dan sifat tanah lempung yang berbeda-beda. Dalam diagram korelasi nilai CBR dan UCS terlihat nilai CBR dan UCS tidak saling berhubungan, dapat dilihat bahwa nila CBR maksimum diperoleh pada penambahan roadbooster 0\% dengan nilai CBR sebesar $76 \%$, sedangkan nilai UCS maksimum diperolehpada penambahan roadbooster $8 \%$ dengan nilai UCS sebesar $8,30 \mathrm{~kg} / \mathrm{m}^{2}$.

\section{DAFTAR PUSTAKA}

Anonim. Roadbooster. 11 Januari 2017.

http://www.roadbooster.com/en/faq.html.

Hardiyatmo, H.C. (2002). Mekanika Tanah I. Edisi ketiga. Gajah Mada University Press. Yogyakarta.

Hardyatmo, H.C. (2006). Mekanika Tanah I. Edisi Keempat. Gajah Mada University Press. Yogyakarta.

Hardyatmo, H.C. (2010). Mekanika Tanah I. Edisi Kelima. Gajah Mada University Press. Yogyakarta.

Hardiyatmo, H.C. (2010). Stabilisasi Tanah Untuk Perkerasan Jalan. Gajah Mada University Press. Yogyakarta.

Muda, A. (2011). Stabilisasi Tanah Lempung Bukit Rawi Menggunakan Pasir Dan Semen. Tesis Bidang Keahlian Geoteknik Jurusan Teknik Sipil. Universitas Lambung Mangkurat. Banjarmasin.

Raharmadi, B. (2011). Pengaruh Semen Terhadap Peningkatan Kekuatan Tanah Sebagai Pondasi Perkerasan Jalan. Tesis Bidang Keahlian Geoteknik Program Studi
Magister Teknik Sipil Program Pascasarjana. Universitas Lambung Mangkurat. Banjarmasin.

Saputra, N.A (2012). Kekuatan Geser Antarmuka Laterit Palangkaraya Dan Geotekstil Berdasarkan Uji Geser Langsung. Tesis Bidang Keahlian Geoteknik Program Studi Magister Teknik Sipil Program Pascasarjana. Universitas Lambung Mangkurat. Banjarmasin. 